\title{
Correlation of Fine Needle Aspiration Cytology with Histopathology in the Diagnosis of Solitary Thyroid Nodule
}

\author{
Manoj Gupta, Savita Gupta, and Ved Bhushan Gupta \\ Department of General Surgery, Government Medical College, Jammu (J®K) 180005, India \\ Correspondence should be addressed to Manoj Gupta, manoj.g.dr@gmail.com
}

Received 7 November 2009; Accepted 28 February 2010

Academic Editor: Paolo Beck-Peccoz

Copyright () 2010 Manoj Gupta et al. This is an open access article distributed under the Creative Commons Attribution License, which permits unrestricted use, distribution, and reproduction in any medium, provided the original work is properly cited.

Background. Fine needle aspiration cytology is considered the gold standard diagnostic test for the diagnosis of thyroid nodules. Fine needle aspiration cytology is a cost effective procedure that provides specific diagnosis rapidly with minimal complications. Based on the cytology findings, patients can be followed in cases of benign diagnosis and subjected to surgery in cases of malignant diagnosis thereby decreasing the rate of unnecessary surgery. Purpose of the present study was to correlate the fine needle aspiration cytology findings with histopathology of excised specimens. Material and Methods. This was a prospective study conducted on 75 consecutive patients between January 2003 and December 2005. All patients with clinically diagnosed solitary thyroid nodule who were clinically and biochemically euthyroid were included for study. Patients with multinodular goitre and who were hypothyroid or hyperthyroid were excluded from the study. Results. The sensitivity, specificity, accuracy, false positive rate, false negative rate, positive predictive value, and negative predictive value of FNAC for the diagnosis of neoplastic solitary thyroid nodules were $80 \%, 86.6 \%, 13.3 \%, 20 \%, 80 \%$, and $86.6 \%$, respectively. Commonest malignancy detected was papillary carcinoma in 12 patients. Conclusions. Fine needle aspiration cytology is a simple, easy to perform, cost effective, and easily repeated procedure for the diagnosis of thyroid cancer. It is recommended as the first line investigation for the diagnosis of solitary thyroid nodule.

\section{Introduction}

Solitary thyroid nodule is defined clinically as the localised thyroid enlargement with apparently normal rest of the gland. Solitary thyroid nodule is a common entity. Majority of these nodules are benign. The main goal of evaluating these nodules is to identify nodules with malignant potential.

A multitude of diagnostic tests like ultrasound, thyroid nuclear scan, and fine needle aspiration cytology (FNAC) is available to the clinician for evaluation of thyroid nodule. FNAC is considered the gold standard diagnostic test in the evaluation of a thyroid nodule, and other tests like ultrasound and nuclear scan should be used in conjunction with FNAC.

FNAC is simple, cost effective, readily repeated, and quick to perform procedure in the outpatient department with excellent patient compliance. Important factor for the satisfactory test includes representative specimen from the nodule and an experienced cytologist to interpret findings. It is often used as the initial screening test for diagnosis of thyroid nodules [1].

The prevalence of thyroid nodules ranges from $4 \%$ to $10 \%$ in the general adult population and from $0.2 \%$ to $1.2 \%$ in children [2]. The majority of clinically diagnosed thyroid nodules are nonneoplastic; only 5\%-30\% are malignant and require surgical intervention [3].

FNAC is, however, not without limitations; accuracy is lower in suspicious cytology and in follicular neoplasms. The main aim of FNAC is to identify nodules that require surgery and those benign nodules that can be observed clinically and decrease the overall thyroidectomy rate in patients with benign diseases. The present study was undertaken to correlate the FNAC findings with histopathology so that rate of unnecessary thyoidectomies in benign pathologies should be avoided. 
TABLE 1: Characteristics of the patients presented with clinically solitary thyroid nodule.

\begin{tabular}{|c|c|}
\hline Characteristic & Total patients $(n=75)$ \\
\hline \multicolumn{2}{|l|}{ Age (in years) } \\
\hline 20-29 & 9 \\
\hline $30-39$ & 33 \\
\hline $40-49$ & 24 \\
\hline $50-59$ & 9 \\
\hline \multicolumn{2}{|l|}{ Sex } \\
\hline Male & 6 \\
\hline Female & 69 \\
\hline \multicolumn{2}{|l|}{ Demography } \\
\hline Plains & 51 \\
\hline Mountains & 24 \\
\hline \multicolumn{2}{|l|}{ Presenting complaint } \\
\hline Neck swelling & 60 \\
\hline Neck pain & 9 \\
\hline Neck discomfort & 6 \\
\hline \multicolumn{2}{|c|}{ Mode of detection of swelling } \\
\hline Self & 60 \\
\hline Others & 15 \\
\hline \multicolumn{2}{|c|}{ Duration of complaints } \\
\hline$<1$ month & 3 \\
\hline $1-12$ months & 24 \\
\hline 1-2 Year & 9 \\
\hline$>2$ years & 39 \\
\hline \multicolumn{2}{|l|}{ Site of swelling } \\
\hline Right lobe & 45 \\
\hline Left lobe & 21 \\
\hline Isthmus & 9 \\
\hline \multicolumn{2}{|l|}{ Treatment history } \\
\hline No & 48 \\
\hline Yes & 27 \\
\hline
\end{tabular}

\section{Material and Methods}

This is a prospective analysis of seventy five consecutive patients of clinically diagnosed solitary thyroid nodule who presented to the Department of Surgery, Government Medical College Jammu, and Department of ENT, SMGS Hospital, Jammu (India) between January 2003 and December 2005.

All patients were evaluated by thorough clinical examination followed by routine investigations including haemogram, renal function tests, liver function tests, chest $\mathrm{X}$-ray, lateral neck X-ray, thyroid function tests and, FNAC.

Inclusion criteria included clinically detected solitary thyroid nodule and euthyroid patients with normal thyroid function tests. Patients with abnormal thyroid function tests (hypothyroid/hyperthyroid) and multiple thyroid nodules were excluded from the study. FNAC was performed with 23 gauge needle, smears were fixed with ether-95\% alcohol solution, and staining was performed using papanicolau's staining. After FNAC, all the patients were subjected to surgery after preoperative preparation and anaesthesia checkup. Thyroidectomy specimen was evaluated by histopathological examination. Specimens were processed in automated tissue processing units and staining was performed with routine haematoxylin and eosin stain.

Correlation of histopathological findings was performed with FNAC. Sensitivity, specificity, accuracy, positive predictive value, and negative predictive value were calculated for neoplastic and carcinomatous lesions.

\section{Results}

A total of 75 patients with solitary thyroid nodule were identified: 6 (8\%) were male and 69 (92\%) were females. Age of the patients ranged from 22 to 58 years with mean age of 38.7 years. Characteristics of the patients were shown in Table 1.

$51(68 \%)$ patients were from plain areas and $24(32 \%)$ were residents of hilly areas. Commonest presentation was neck swelling in $60(80 \%)$ of the patients. Duration of complaints ranged from six days to twenty years and mean duration was 1.7 years.

FNAC results revealed 39 (52\%) cases as colloid nodular goitre, $12(16 \%)$ as follicular neoplasm, $9(12 \%)$ as papillary carcinoma, $6(8 \%)$ as hurthle cell lesions, $6(8 \%)$ as benign cystic lesions, and $3(4 \%)$ cases as suspected of malignancy.

Histopathological examination of excised specimens showed $42(56 \%)$ cases as colloid nodular goitre, $12(16 \%)$ as follicular adenoma, $12(16 \%)$ as papillary carcinoma, 3 (4\%) as hurthle cell adenoma, $3(4 \%)$ as hurthle cell changes with capsular invasion and, 3 (4\%) as hashimoto's thyroiditis.

Comparison of FNAC with histopathological findings was performed. 45 cases were diagnosed as colloid nodular goitre and benign cystic lesions by FNAC. 39 of these cases were nonneoplastic lesions, 3 as papillary carcinoma and 3 as follicular adenoma in histopathological examination (Table 2).

30 cases were diagnosed as neoplastic lesions (follicular neoplasm, hurthle cell lesions, papillary carcinoma, and suspected malignancy) by FNAC. 3 of these cases were nonneoplastic lesions, 12 were benign neoplastic lesions, 12 were carcinoma, and 3 cases of suspected malignancy were diagnosed as hashimoto's thyroiditis on histopathological examination (Table 3 ).

False positive and false negative results were shown in Table 4.

Statistical analysis of neoplastic lesions (Table 5) showed sensitivity, specificity, accuracy, false positive rate, false negative rate, positive predictive value, and negative predictive value of FNAC to be $80 \%, 86.6 \%, 84 \%, 13.3 \%, 20 \%, 80 \%$, and $86.6 \%$, respectively whereas statistical analysis of carcinomatous lesions (Table 6) showed sensitivity, specificity, accuracy, false positive rate, false negative rate, positive predictive value, and negative predictive value of FNAC to be $80 \%, 95 \%, 92 \%, 5 \%, 20 \%, 80 \%$, and $95 \%$.

A total of 15 cases of solitary thyroid nodules were diagnosed as having malignant and the most common malignant lesion detected was papillary carcinoma, 12 out of $15(80 \%)$. 
TABLE 2: Nonneoplastic lesions diagnosed by FNAC and their comparison with histopathological diagnosis.

\begin{tabular}{lclrl}
\hline FNAC report & Number of patients $(n=45)$ & Histopathological report & Number of patients $(n=45)$ & Remarks \\
\hline $\begin{array}{l}\text { Colloid nodular } \\
\text { goitre \& benign cystic }\end{array}$ & \multirow{2}{*}{45} & Colloid nodular goitre & 39 & True negative \\
lesions & & Follicular adenoma & 3 & False negative \\
& & Papillary carcinoma & 3 & False negative \\
\hline
\end{tabular}

TABLE 3: Benign or suspicious neoplastic lesions diagnosed by FNAC and their comparison with histopathological diagnosis.

\begin{tabular}{lclcc}
\hline FNAC report & Number of patients $(n=30)$ & Histopathological report & Number of patients $(n=30)$ & Remarks \\
\hline Follicular neoplasm & 12 & Follicular adenoma & 9 & True positive \\
& & Colloid nodular goitre & 3 & False positive \\
Hurthle cell tumours & 6 & Hurthle cell adenoma & 3 & True positive \\
& 9 & Hurthle cell carcinoma & 9 & True positive \\
Papillary carcinoma & 3 & Papillary carcinoma & 3 & True positive \\
Suspected malignancy & & Hashimoto thyroiditis & False positive \\
\hline
\end{tabular}

TABLE 4: Summary of false positive and false negative results of FNAC.

\begin{tabular}{ll}
\hline FNAC finding & Histopathology result \\
\hline False positive & \\
Follicular neoplasm & $\begin{array}{l}\text { Colloid nodular goitre } \\
\text { Suspected malignancy }\end{array}$ \\
\hline $\begin{array}{l}\text { False negative } \\
\text { Colloid nodular goitre }\end{array}$ & Follicular adenoma \\
Colloid nodular goitre & Papillary carcinoma \\
\hline
\end{tabular}

TABLE 5: Statistical analysis for neoplastic lesions.

\begin{tabular}{lcc}
$\begin{array}{l}\text { Test being evaluated } \\
\text { (FNAC) }\end{array}$ & \multicolumn{2}{c}{$\begin{array}{c}\text { Reference standard test (Histopathology) } \\
\text { Positive }\end{array}$} \\
\hline Positive + suspicious & 24 & Negative \\
Negative & 6 & 39 \\
\hline
\end{tabular}

Sensitivity $=80 \%$, specificity $=86.6 \%$, accuracy $=84 \%$, false positive result $=13.3 \%$, false negative result $=20 \%$, positive predictive value $=80 \%$, and negative predictive value $=86.6 \%$.

TABLE 6: Statistical analysis for carcinomatous lesions.

\begin{tabular}{lcc}
\hline $\begin{array}{l}\text { Test being evaluated } \\
\text { (FNAC) }\end{array}$ & $\begin{array}{c}\text { Reference standard test (Histopathology) } \\
\text { Positive }\end{array}$ & Negative \\
\hline Positive + suspicious & 12 & 3 \\
Negative & 3 & 57 \\
\hline
\end{tabular}

Sensitivity $=80 \%$, specificity $=95 \%$, accuracy $=92 \%$, false positive result $=$ $5 \%$, false negative result $=20 \%$, positive predictive value $=80 \%$, and negative predictive value $=95 \%$.

\section{Discussion}

In present study, the age of patients ranged from 22 to 58 years with mean of 38.72 years. This age range and mean incidence is slightly lower as compared with previous studies [4-6]. We found that majority of patients (44\%) were in their third decade of life. This is in accordance with the study by Dorairajan and Jayashree [7]. Solitary thyroid nodules were
4-9 times more common in females as compared to males $[7,8]$. Our study showed that solitary thyroid nodules were 11 times more common in females than males.

The false negative rate was $20 \%$ in cases of neoplastic lesions. It constitutes a serious limitation of this technique since these malignant lesions would go untreated. The incidence of false negative results is as low as $1 \%$ to as high as $30 \%[9,10]$. The false positive rate was $13.3 \%$ for neoplastic lesions but none of these lesions were malignant.

Comparison of results of present study with various previous studies is shown in Table 7.

The methods used for the calculation of sensitivity, specificity, accuracy, positive predictive value, and negative predictive value were similar to previous studies $[11,12]$. Sensitivity and accuracy of FNAC for detection of neoplasm were $80 \%$ and $84 \%$, respectively, whereas they were $76 \%$ and $69 \%$, respectively, in a study by Cusick et al. [12].

The sensitivity, specificity, and accuracy of FNAC for solitary thyroid nodules were $80 \%, 86.6 \%$, and $84 \%$, respectively, in our study whereas sensitivity, specificity, and accuracy of FNAC were $93.5 \%, 75 \%$, and $79.6 \%$, respectively, in a study by Bouvet et al. [8] and 79\%, 98.5\%, and 87\%, respectively, in a study by Kessler et al. [13].

In our study 15 cases were found to be malignant on histopathological examination (12 papillary carcinoma and 3 hurthle cell lesions). It is to be stressed that all cases of papillary carcinoma diagnosed by FNAC were papillary carcinoma on histopathological examination also. This is in accordance with previous studies $[7,13]$. The incidence of malignancy in this study was $20 \%$ which is in accordance with study by Dorairajan and Jayashree [7]. The incidence of malignancy can be as high as $43.6 \%$ [8].

The incidence of papillary carcinoma in the present study was $80 \%$. In the literature, incidence of papillary carcinoma varies from $50 \%$ to $80 \%[7,8,14]$. Brooks et al. found that preoperative FNAC had no direct impact on the selection of the surgical procedure and intraoperative frozen section added very little to surgical management [15].

The diagnostic accuracy of Correlation between FNAC diagnosis and final histological diagnosis, intraoperative 
TABLE 7: Comparison of results of present study with previous studies.

\begin{tabular}{lccccccc}
\hline Study & Year & Number of patients & Sensitivity & Specificity & Accuracy & Negative predictive value & Positive predictive value \\
\hline Al-Sayer et al. & 1985 & 70 & 86 & 93 & 92 & 96 & 80 \\
Cusick et al. & 1990 & 283 & 76 & 58 & 69 & 64 & 72 \\
Bouvet et al. & 1992 & 78 & 93.5 & 75 & 79.6 & 88.2 & 85.3 \\
Afroze et al. & 2002 & 170 & 61.9 & 99.3 & 94.5 & 94.7 & 92.8 \\
KO HM et al. & 2003 & 207 & 78.4 & 98.2 & 84.4 & 66.3 & 99 \\
Kessler et al. & 2005 & 170 & 79 & 98.5 & 87 & 86.6 & 98.7 \\
Present series & 2006 & 75 & 80 & 86.6 & 84 & 86.6 & 80 \\
\hline
\end{tabular}

frozen section diagnoses without intraoperative cytology and final histological diagnoses, and intraoperative frozen section diagnoses associated with intraoperative cytology and final histological diagnoses were $88.8 \%, 88.8 \%$, and $95.7 \%$, respectively [16].

Frozen section should be considered unnecessary because it does not affect the intraoperative decision making. The sensitivity, specificity, positive predictive value, negative predictive value, and accuracy were $13.0 \%, 97.3 \%, 37.5 \%$, $90.0 \%$, and $88.1 \%$ for FNA cytology, and $17.4 \%, 100 \%$, $100 \%, 90.8 \%$, and $91.0 \%$ for FS, respectively [17].

Analysis of data from seven series showed a false-negative rate of $1 \%$ to $11 \%$, a false-positive rate of $1 \%$ to $8 \%$, a sensitivity of $65 \%$ to $98 \%$, and a specificity of $72 \%$ to $100 \%$ [18]. The results are consistent with our study.

Cytologic and histologic diagnoses were compared in 4069 patients and the sensitivity and specificity of FNAC were found to be $91.8 \%$ and $75.5 \%$, respectively [19].

\section{Conclusions}

We concluded that FNAC diagnosis of malignancy is highly significant and such patients should be subjected to surgery. A benign FNAC diagnosis should be viewed with caution as false negative results do occur and these patients should be followed up and any clinical suspicion of malignancy even in the presence of benign FNAC requires surgery.

\section{References}

[1] Y. C. Oertel, "Fine-needle aspiration and the diagnosis of thyroid cancer," Endocrinology and Metabolism Clinics of North America, vol. 25, no. 1, pp. 69-91, 1996.

[2] E. C. Ridgway, "Clinical evaluation of solitary thyroid nodules," in The Thyroid: A Fundamental and Clinical Text, pp. 1377-1385, G. B. Lippincott, Philadelphia, Pa, USA, 1986.

[3] R. Bakhos, S. M. Selvaggi, S. DeJong, et al., "Fine needle aspiration of the thyroid: rate and causes of cytopathologic discordance," Diagn Cytopathol, vol. 23, no. 4, pp. 233-237, 2000.

[4] S. Agrawal, "Diagnostic accuracy and role of fine needle aspiration cytology in management of thyroid nodules," Journal of Surgical Oncology, vol. 58, no. 3, pp. 168-172, 1995.

[5] R. Bakhos, S. M. Selvaggi, S. Dejong, et al., "Fine-needle aspiration of the thyroid: rate and causes of cytohistopathologic discordance," Diagnostic Cytopathology, vol. 23, no. 4, pp. 233 237, 2000.
[6] J. L. Morgan, J. W. Serpell, and M. S. P. Cheng, "Fine-needle aspiration cytology of thyroid nodules: how useful is it?" ANZ Journal of Surgery, vol. 73, no. 7, pp. 480-483, 2003.

[7] N. Dorairajan and N. Jayashree, "Solitary nodule of the thyroid and the role of fine needle aspiration cytology in diagnosis," Journal of the Indian Medical Association, vol. 94, no. 2, pp. 50-52, 1996.

[8] M. Bouvet, J. I. Feldman, G. N. Gill, et al., "Surgical management of the thyroid nodule: patient selection based on the results of fine-needle aspiration cytology," Laryngoscope, vol. 102, no. 12, pp. 1353-1356, 1992.

[9] R. C. Hamaker, M. I. Singer, R. V. DeRossi, and W. W. Shockley, "Role of needle biopsy in thyroid nodules," Archives of Otolaryngology, vol. 109, no. 4, pp. 225-228, 1983.

[10] M. Radetic, Z. Kralj, and I. Padovan, "Reliability of aspiration biopsy in thyroid nodes: study of 2190 operated patients.," Tumori, vol. 70, no. 3, pp. 271-276, 1984.

[11] H. M. Al-Sayer, Z. H. Krukowski, V. M. M. Williams, and N. A. Matheson, "Fine needle aspiration cytology in isolated thyroid swellings: a prospective two year evaluation," British Medical Journal, vol. 290, no. 6480, pp. 1490-1492, 1985.

[12] E. L. Cusick, C. A. MacIntosh, Z. H. Krukowski, V. M. M. Williams, S. W. B. Ewen, and N. A. Matheson, "Management of isolated thyroid swelling: a prospective six year study of fine needle aspiration cytology in diagnosis," British Medical Journal, vol. 301, no. 6747, pp. 318-321, 1990.

[13] A. Kessler, H. Gavriel, S. Zahav, et al., "Accuracy and consistency of fine-needle aspiration biopsy in the diagnosis and management of solitary thyroid nodules," Israel Medical Association Journal, vol. 7, no. 6, pp. 371-373, 2005.

[14] R. J. De Vos Tot Nederveen Cappel, N. D. Bouvy, H. J. Bonjer, J. M. Van Muiswinkel, and S. Chadha, "Fine needle aspiration cytology of thyroid nodules: how accurate is it and what are the causes of discrepant cases?" Cytopathology, vol. 12, no. 6, pp. 399-405, 2001.

[15] A. D. Brooks, A. R. Shaha, W. DuMornay, et al., "Role of fineneedle aspiration biopsy and frozen section analysis in the surgical management of thyroid tumors," Annals of Surgical Oncology, vol. 8, no. 2, pp. 92-100, 2001.

[16] F. Basolo, C. Ugolini, A. Proietti, P. Iacconi, P. Berti, and P. Miccoli, "Role of frozen section associated with intraoperative cytology in comparison to FNA and FS alone in the management of thyroid nodules," European Journal of Surgical Oncology, vol. 33, no. 6, pp. 769-775, 2007.

[17] F. Lumachi, S. Borsato, A. Tregnaghi, et al., "FNA cytology and frozen section examination in patients with follicular lesions of the thyroid gland," Anticancer Research, vol. 29, no. 12, pp. 5255-5257, 2009. 
[18] H. Gharib and J. R. Goellner, "Fine-needle aspiration biopsy of the thyroid: an appraisal," Annals of Internal Medicine, vol. 118, no. 4, pp. 282-289, 1993.

[19] C. Ravetto, L. Colombo, and M. E. Dottorini, "Usefulness of fine-needlein the diagnosis of thyroid carcinoma: a retrospective study in 37,895 patients," Cancer, vol. 90, no. 6, pp. 357363,2000 . 


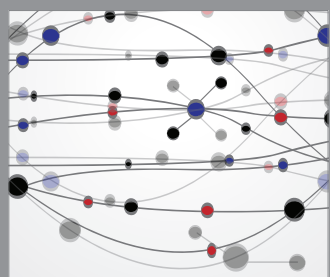

The Scientific World Journal
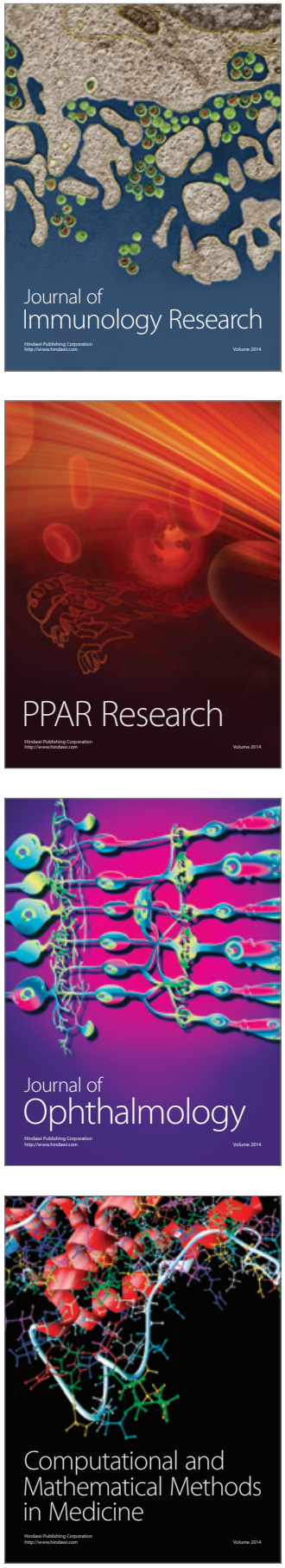

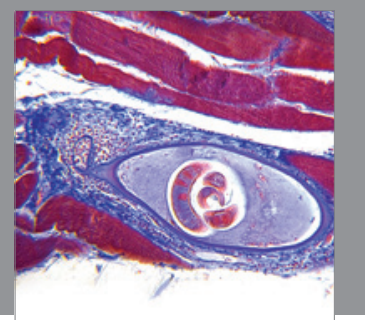

Gastroenterology

Research and Practice
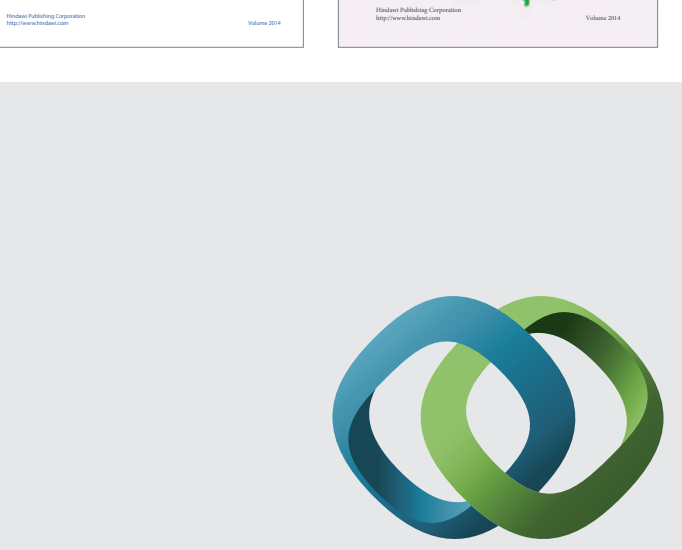

\section{Hindawi}

Submit your manuscripts at

http://www.hindawi.com
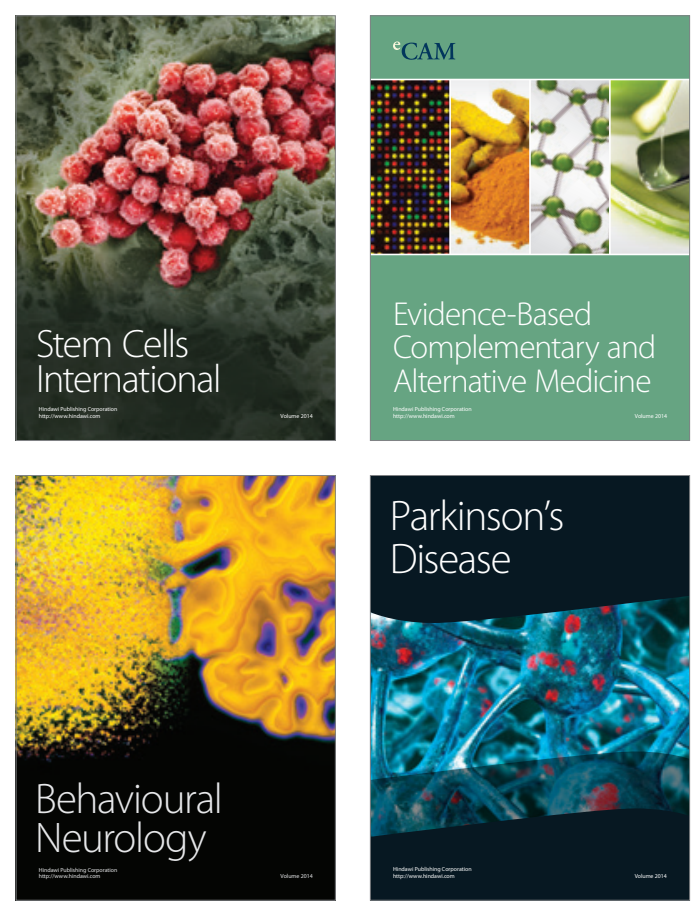

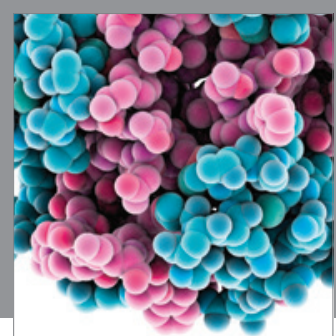

Journal of
Diabetes Research

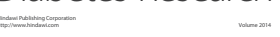

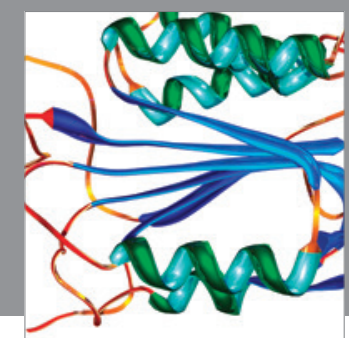

Disease Markers
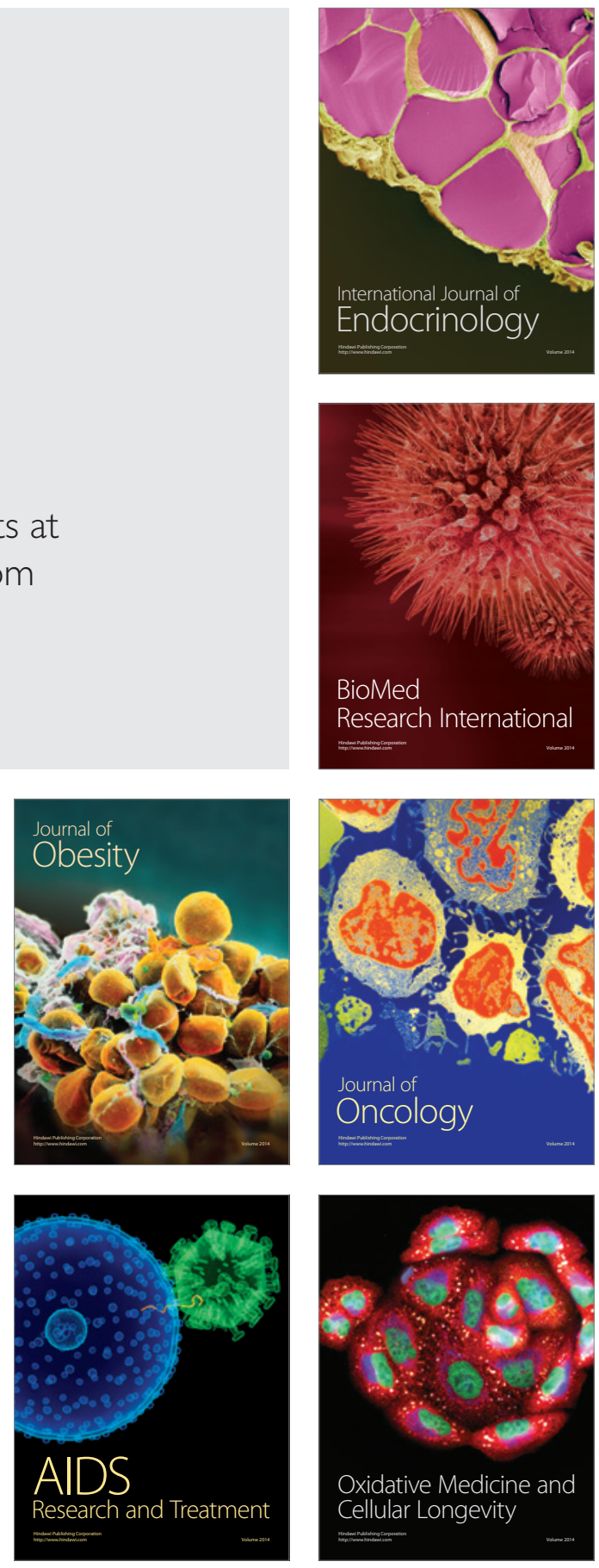